\title{
Faktor yang Berhubungan dengan Terjadinya Unmet Need KB pada Pasangan Usia Subur (PUS) di Kota Yogyakarta
}

\author{
Susiana Sariyati ${ }^{1}$, Sundari Mulyaningsih ${ }^{2}$, Sri Sugiharti ${ }^{3}$ \\ 1,2,3Sekolah Tinggi IImu Kesehatan Alma Ata Yogyakarta \\ Jalan Ringroad Barat Daya No 1 Tamantirto, Kasihan, Bantul, Yogyakarta
}

\begin{abstract}
Abstrak
Masalah kependudukan tetap menjadi isu yang sangat penting dan mendesak, utamanya yang berkaitan dengan aspek pengendalian kualitas penduduk, peningkatan kualitas penduduk dan pengarahan mobilitas penduduk, jika dikaitkan dengan potensi ancaman ledakan penduduk kedepan. Tujuan penelitian ini adalah mengetahui faktor-faktor berhubungan dengan terjadinya unmet need KB pada pasangan usia subur (PUS) di Kota Yogyakarta. Jenis penelitian menggunakan metode deskriptif. Populasi dalam penelitian ini adalah seluruh pasangan usia subur (PUS) di Kota Yogyakarta. Cara atau teknik pengambilan sampel dilakukan dengan teknik Probability Proportional to Size (PPS). Sampel dalam penelitian ini adalah pasangan usia subur di Kota Yogyakarta yang diambil dari 30 RW dalam 30 kelurahan, yaitu sejumlah 779 responden. Hasil penelitian tidak ada hubungan yang signifikan antara umur istri dengan kejadian unmet need, tidak ada hubungan yang signifikan antara pendidikan istri dengan kejadian unmet need, dan tidak ada hubungan yang signifikan antara jumlah anak masih hidup dengan kejadian unmet need KB.
\end{abstract}

Kata Kunci: unmet need, pasangan usia subur

\section{Factors Associated with Unmet Need Family Planning among Reproductive Age Couples in Yogyakarta}

\begin{abstract}
The problem of population is important big issues and urgent, primarily related with aspects of the quality of population control, improving the quality of population and mobility of population, if its associated with the potential threat of explosion of population. The purpose of this study was to know factors associated with unmet need family planning among reproductive age couples in Yogyakarta. This study used descriptive method. The populations of this study were all of reproductive age couples in Yogyakarta. The sampling technique was done by probability proportional to size resulted on 779 respondents of reproductive age couples from 30 sub village in 30 village in Yogyakarta. The results of study showed that there was no significant relationship between respondent ages and unmet need, no significant relationship between wife education and unmet need, and no significant relationship between the number of children still live and unmet need.
\end{abstract}

Keywords: unmet need, reproductive age couples

Info Artikel:

Artikel dikirim pada 28 Oktober 2015

Artikel diterima pada 30 Oktober 2015 


\section{PENDAHULUAN}

Indonesia merupakan negara yang dilihat yang dilihat dari jumlah penduduknya ada pada posisi keempat didunia, dengan laju pertumbuhan yang masih relatif tinggi. Esensi tugas program Keluarga Berencana (KB) dalam hal ini telah jelas yaitu menurunkan fertilitas agar dapat mengurangi beban pembangunan demi terwujudnya kebahagiaan dan kesejahteraan bagi rakyat dan bangsa Indonesia. Seperti yang disebutkan dalam UU No. 10 tahun 1992 tentang Perkembangan Kependudukan dan Pembangunan Keluarga sejahtera(1).

Masalah kependudukan tetap menjadi isu yang sangat penting dan mendesak, utamanya yang berkaitan dengan aspek pengendalian kualitas penduduk, peningkatan kualitas penduduk dan pengarahan mobilitas penduduk, jika dikaitkan dengan potensi ancaman ledakan penduduk kedepan. Saat ini penduduk dunia telah mencapai 7 miliyar jiwa atau bertambah 1 milyar jiwa hanya dalam waktu 10 tahun. Berdasarkan hasil sensus tahun 2010, penduduk Indonesia bertambah 32,5 juta jiwa, dan rata-rata pertumbuhan 1,49\%. Apabila laju pertambahan penduduk masih 1,49\% seperti sekarang, maka jumlah penduduk Indonesia pada tahun 2045 menjadi 450 juta jiwa(2).

KB merupakan upaya untuk meningkatkan kepedulian dan peran serta masyarakat melalui pendewasaan usia perkawinan, pengaturan kelahiran, pembinaan ketahanan keluarga, dan peningkatan kesejahteran keluarga guna mewujudkan keluarga kecil, bahagia dan sejahtera(1).

Program KB di Indonesia telah diakui secara Nasional dan Internasional sebagai salah satu program yang telah berhasil menurunkan angka fertilitas secara nyata. Hal ini dapat dilihat dari TFR Indonesia hasil survei SDKI 2003 sebesar 2,4 dan menurun menjadi 2,3 pada SDKI 2007. Namun program keluarga berencana di Indonesia ini masih tetap menghadapi beberapa masalah penting dalam upaya mempertahankan program yang selama ini telah berhasil dilaksanakan. Salah satu masalah dalam pengelolaan program KB yaitu masih tingginya angka unmet need KB. Jumlah pasangan usia subur (PUS) yang ingin menunda kehamilan atau tidak menginginkan tambahan anak tetapi tidak ber-KB (Unmet Need KB), meningkat dari 8,6\% (SDKI, 2002-2003) menjadi 9,1\% (SDKI, 2007), dimana diharapkan pada akhir tahun 2014 dapat diturunkan menjadi sebesar $5 \%(3)$.
Dalam program KB di Indonesia, jika diperhatikan terjadi peningkatan jumlah PUS yang ingin menunda kehamilan atau tidak menginginkan tambahan anak tetapi tidak menggunakan alat kontrasepsi (unmet need KB), yaitu meningkat dari 8,6\% menjadi 9,1\%(4). Hal ini sangat memprihatinkan karena diharapkan pada akhir tahun 2014 prevalensi unmeet need ini dapat diturunkan menjadi sebesar $5 \%(5)$.

Provinsi Daerah Istimewa Yogyakarta (DIY) merupakan salah satu provinsi di Indonesia yang mempunyai unmet need yang tinggi, pada tahun 2012 di Provinsi DIY peserta KB aktif mencapai $73,29 \%$ dari 34.737 PUS, dan untuk unmet need mencapai $13,69 \%$ dari 5.729 PUS dengan rincian: Ingin Anak Tunda (IAT) 5,29\% dari 2.507 PUS, Tidak Ingin Anak Lagi (TIAL) 6,80 dari 3.222 PUS(5).

Berdasarkan penelitian Handrina, alasan istri yang ingin mengontrol kelahiran tetapi tidak menggunakan alat kontrasepsi (unmet need) disebabkan dua alasan yaitu pertama, sumber daya manusia (SDM) yang masih rendah dengan pola pikir yang tradisional dilatar belakangi oleh faktor keagamaan dan kultur budaya sehingga kesalahan dalam menentukan pilihan pemakaian alat kontrasepsi dapat menimbulkan efek samping terutama gangguan kesehatan bagi perempuan/ istri. Kedua, adanya larangan dari suami. Kedua alasan tersebut berkaitan dengan faktor penyebab yaitu keterjangkauan program KB terkait dengan berkurangnya jumlah penyuluh $\mathrm{KB}$ dan kurangnya pengetahuan PUS tentang alat kontrasepsi, serta lemahnya pelaksanaan program KB terkait dengan menentukan pilihan terhadap pemakaian alat kontrasepsi(6). Tujuan penelitian ini adalah mengetahui faktor-faktor berhubungan dengan terjadinya unmet need KB pada pasangan usia subur (PUS) di Kota Yogyakarta tahun 2013.

\section{BAHAN DAN METODE}

Jenis Penelitian yang akan digunakan adalah metode deskriptif. Populasi dalam penelitian ini seluruh pasangan usia subur (PUS) di Kota Yogyakarta yang berjumlah 47.399 responden. Cara atau teknik pengambilan sampel dalam penelitian ini dilakukan dengan teknik probability proportional to size (PPS). Sampel dalam penelitian ini adalah pasangan usia subur di kota Yogyakarta yang diambil dari $30 \mathrm{RW}$ dalam 30 kelurahan, yaitu 
sejumlah 750 orang dan terdapat sampel tambahan sebanyak 29 orang sehingga total sampel menjadi 779. Sampel untuk pendekatan kualitatif diambil secara purposive sampling sebanyak 5 responden (PPKBD dan penyuluh KB). Data yang dikumpulkan adalah data primer dan data sekunder. Data primer diperoleh melalui wawancara dengan responden berdasarkan kuesioner. Analisa data adalah analisis univarat yaitu untuk mendeskripsikan masing-masing variabel penelitian menggunakan distribusi frekuensi dan rata-rata.

\section{HASIL DAN BAHASAN}

\section{Hubungan antara Unmet Need dengan Umur}

Jumlah responden yang menjadi subjek penelitian dalam penelitian ini adalah 779 responden. Responden kemudian dikelompokkan berdasarkan umur yang disajikan dalam Tabel 1.

Berdasarkan Tabel 1 diketahui bahwa responden menurut umur istri sebagian besar yang unmet need KB berusia $>35$ tahun yaitu sebanyak 85 orang $(58,22 \%)$, sedangkan untuk responden yang berusia $<20$ yaitu 2 orang $(1,37 \%)$. Hasil perhitungan uji statistik menggunakan chi-square seperti disajikan pada tabel dapat diperoleh $p$-value $0,291>\alpha(0,05)$ sehingga dapat disimpulkan tidak ada hubungan yang signifikan antara umur istri dengan kejadian unmet need.

Terjadinya unmet need berdasarkan penelitian ini dapat terjadi pada berbagai umur baik pada umur reproduksi muda maupun reproduksi tua. Dalam penelitian ini kejadian unmet need paling banyak adalah responden yang berusia $>35$ tahun. Berdasarkan hasil wawancara mereka beranggapan bahwa pada usia tersebut sudah bukan masa reproduktif lagi dan menganggap dirinya sudah tua sehingga kemungkinan untuk terjadi kehamilan sangat kecil.
Anggapan responden tersebut tidak benar jika pada usia $>35$ tahun adalah masa berhentinya reproduksi seorang wanita tetapi usia tersebut masih dapat terjadi kehamilan, masa seorang wanita dapat bereproduksi adalah jika seorang wanita berumur 15-49 tahun.

Hasil penelitian ini didukung dengan penelitian Odumosu dalam Fitriyah, yang menemukan bahwa peluang tertinggi kejadian unmet need $\mathrm{KB}$ justru pada kelompok umur yang lebih tua. Penelitian tersebut menjelaskan bahwa tidak ada rumusan umur yang spesifik terhadap kejadian unmet need $K B$, namun, pada kelompok umur yang lebih tua, semakin berkembang asumsi yang salah mengenai fertilitas, yaitu semakin tua umur seseorang maka akan semakin kecil atau menurun risiko seseorang tersebut sejalan dengan argumen yang menyebutkan bahwa terjadinya unmet need KB dikarenakan adanya persepsi yang salah terhadap kemampuan untuk hamil(7). Penelitian ini sama dengan penelitian Fitriyah yang menyatakan bahwa bila suami dan istri yang berada dikelompok usia tua (46 tahun ke atas) semakin berpeluang menyebabkan unmet need $\mathrm{KB}(7)$.

Penelitian Isa berdasarkan hasil SDKI 2007 menunjukan bahwa terdapat hubungan yang signifikan antara umur responden dan status unmet need atau kebutuhan KB yang tidak terpenuhi karena hal ini disebabkan oleh semakin tua umur wanita maka dia akan semakin memiliki pengalaman lebih dalam meggunakan KB sehingga dia bisa memilih alat atau metode $\mathrm{KB}$ yang cocok dan memperkecil untuk mengalami kebutuhan KB yang tidak terpenuhi. Umur wanita akan memepengaruhi aspek pengalaman secara psikologis dan fisiologis dalam menggunakan KB dan tidak hanya mempengaruhi motivasi wanita untuk mengontrol fertilitasnya(8).

Tabel 1. Hubungan antara Unmet Need dengan Umur di Kota Yogyakarta

\begin{tabular}{|c|c|c|c|c|c|}
\hline \multirow{3}{*}{ Umur Istri } & \multicolumn{4}{|c|}{ Status Unmet Need } & \multirow{3}{*}{$p$-value } \\
\hline & \multicolumn{2}{|c|}{ Unmet Need } & \multicolumn{2}{|c|}{ Met Need } & \\
\hline & $\mathbf{n}$ & $\%$ & $\mathbf{n}$ & $\%$ & \\
\hline$<20$ & 2 & 1,37 & 11 & 1,74 & \\
\hline $20-35$ & 59 & 40,41 & 299 & 47,24 & 0,291 \\
\hline$>35$ & 85 & 58,22 & 323 & 51,02 & \\
\hline Total & 146 & 18,74 & 633 & 81,26 & \\
\hline
\end{tabular}

Sumber: Data Primer Tahun 2013 


\section{Hubungan antara Unmet Need dengan Pendidikan}

Responden dikelompokkan berdasarkan pendidikan yaitu: tidak tamat/tamat SD, tamat SMP/ sederajat, dan tamat >SMA/sederajat yang disajikan dalam Tabel 2.

Tabel 2 menunjukan sebagian besar responden yang unmet need KB berpendidikan tamat >SMA/ sederajat yaitu sebanyak 93 orang $(63,7 \%)$, sedangkan yang paling sedikit yang berpendidikan tidak tamat/tamat SD yaitu 17 orang (11,64\%). Hasil perhitungan uji statistik menggunakan chi-square seperti disajikan pada tabel dapat diperoleh $p$-value $0,057>\alpha(0,05)$ sehingga dapat disimpulkan tidak ada hubungan yang signifikan antara pendidikan istri dengan kejadian unmet need.

Penelitian ini menunjukkan semakin tinggi pendidikan seseorang maka semakin besar kejadian unmet need. Semakin mengetahui tentang kontrasepsi maka semakin tinggi seseorang untuk tidak menggunakan kontrasepsi. Hal ini dikarenakan seseorang sudah mengetahui pengetahuan bagaimana cara mencegah kehamilan secara alami sehingga mereka tidak bersedia menggunakan kontrasepsi secara modern atau kontrasepsi yang menggunakan alat. Selain itu juga seseorang tidak menggunakan kontrasepsi disebabkan karena pengalaman negatif dari orang lain seperti efek sampingnya jika menggunakan kontrasepsi dan pengalaman pernah mengalami kegagalan menggunakan kontrasepsi, sehingga meskipun pendidikan seseorang tinggi tetap terjadi unmet need.

Hasil penelitian ini didukung dengan penelitian Aryal, et al dalam Isa terhadap data survei demografi dan kesehatan di Nepal yang menemukan bahwa kejadian unmet need ditemukan pada responden wanita yang memiliki pendidikan tinggi. Sejalan dengan penelitian Isa yang menyatakan bahwa tidak ada hubungan yang signifikan antara status unmet need dengan tingkat pendidikan tertinggi yang pernah diperoleh responden(8).
Berbeda dengan penelitian Westoff dan Bankole dalam Isa yang menemukan bahwa semakin tinggi tingkat pendidikan ibu, maka semakin rendah persentasi terjadinya unmet need. Pendidikan bisa mempengaruhi kondisi unmet need karena orang berpendidikan akan memiliki pengetahuan yang lebih tentang permasalahan kesehatan, termasuk kesehatan reproduksi, sehingga mereka bisa lebih mengerti mengenai alat atau cara KB tertentu beserta pengaruhnya pada kesehatan. Dengan demikian, mereka bisa menentukan alat atau cara yang ingin digunakan dalan ber-KB, sehingga dapat lebih menghindari kemungkinan terjadinya unmet need(8).

\section{Hubungan antara Unmet Need dengan Jumlah Anak Masih Hidup}

Responden dikelompokkan berdasarkan jumlah anak masih hidup yaitu: tidak memiliki anak, 1-2 anak, dan $>2$ anak yang disajikan dalam Tabel 3 .

Tabel 3 menunjukan bahwa menurut jumlah anak hidup sebagian besar responden unmet need KB yang memiliki anak 1-2 anak yaitu sebanyak 110 orang $(75,34 \%)$, sedangkan paling sedikit responden yang tidak memiliki anak yaitu 4 orang $(2,74 \%)$. Hasil perhitungan uji statistik menggunakan chi-square diperoleh $p$-value $0,061>a(0,05)$ sehingga dapat disimpulkan tidak ada hubungan yang signifikan antara jumlah anak masih hidup dengan kejadian unmet need KB.

Hasil penelitian ini menunjukkan bahwa unmet need KB dapat terjadi pada paritas rendah maupun paritas tinggi. Ada sebagian pasangan usia subur ingin menunda kehamilan, menjarangkan atau mengakhiri kehamilan tetapi tidak menggunakan kontrasepsi dengan alasan takut efek samping jika menggunakan kontrasepsi dan jika menggunakan kontrasepsi takut jika kembali kesuburan tidak segera.

Penelitian Sahoo dan Palacio dalam Santy berpendapat bahwa pola penggunaan kontrasepsi berbeda antara perempuan dengan paritas tinggi

Tabel 2. Hubungan antara Unmet Need dengan Pendidikan di Kota Yogyakarta

\begin{tabular}{lccccc}
\hline \multirow{2}{*}{ Pendidikan Istri } & \multicolumn{5}{c}{ Status Unmet need } \\
& Unmet need & met & need & \multirow{2}{*}{ p-value } \\
\cline { 2 - 5 } & $\mathbf{n}$ & $\%$ & $\mathbf{n}$ & $\%$ & \\
\hline Tidak Tamat/Tamat SD & 17 & 11,64 & 37 & 5,84 & 0,057 \\
Tamat SMP/Sederajat & 36 & 24,66 & 134 & 21,17 & \\
Tamat >SMA/Sederajat & 93 & 63,7 & 462 & 72,99 & \\
Total & 146 & 18,74 & 633 & 81,26 & \\
\hline
\end{tabular}

Sumber: Data Primer Tahun 2013 
Tabel 3. Hubungan antara Unmet Need dengan Jumlah Anak Masih

Hidup di Kota Yogyakarta

\begin{tabular}{lccccc}
\hline \multirow{2}{*}{$\begin{array}{c}\text { Jumlah Anak Masih } \\
\text { Hidup }\end{array}$} & \multicolumn{4}{c}{ Status Unmet Need } & \multirow{2}{*}{ p-value } \\
\cline { 2 - 5 } & \multicolumn{1}{c}{ Unmet Need } & \multicolumn{2}{c}{ Met Need } & \\
\cline { 2 - 5 } & $\mathbf{n}$ & $\mathbf{\%}$ & $\mathbf{n}$ & $\%$ & \\
\hline 0=tidak memiliki anak & 4 & 2,74 & 53 & 8,38 & \\
1-2 anak & 110 & 75,34 & 454 & 71,72 & 0,061 \\
>2 anak & 32 & 21,92 & 126 & 19,90 & \\
Total & 146 & 18,74 & 633 & 81,26 & \\
\hline
\end{tabular}

Sumber: Data Primer Tahun 2013

dan paritas rendah. Penggunaan kontrasepsi meningkat pada perempuan dengan paritas tinggi. Jumlah dan jenis kelamin anak yang hidup memiliki pengaruh besar terhadap penerimaan metode Keluarga Berencana. Semakin banyak jumlah anak masih hidup maka akan meningkatkan penggunaan kontrasepsi. Perempuan yang memiliki satu orang anak hidup penggunaan kontrasepsi lebih rendah dibandingkan yang memiliki dua atau lebih dari tiga orang anak. Perempuan dengan jumlah anak yang sedikit memliki keinginan untuk medapatkan anak dengan jenis kelamin yang berbeda(9).

Jumlah anak ideal dalam keluarga di Nepal menurut Karki dalam Triana adalah 3 orang. Pada saat jumlah anak masih sedikit, keinginan suami untuk menambah anak mendominasi pilihan pasangan(10). Menurut Taluro dalam Triana di Ethopia sebanyak $60,3 \%$ suami menginginkan anak dalam jumlah banyak, meski rata-rata jumlah anak hidup mencapai 3 alasannya karena anak merupakan aset baik secara ekonomi maupun sosial(10). Menghendaki anak dalam jumlah banyak dengan alasan ekonomi berlaku di masyarakat tradisional. Jumlah anak ideal di masyarakat tradisional menurut Wilopo sekitar 4-8 anak(10). Menurut laporan SDKI tahun 2007, di Indonesia ada $41 \%$ wanita kawin dan $48 \%$ pria kawin berkeinginan mempunyai anak lagi. Keinginan menghentikan kelahiran pada wanita tersebut meningkat setelah mempunyai 2 anak atau lebih(11).

\section{SIMPULAN DAN SARAN}

Berdasarkan hasil penelitian dapat disimpulkan bahwa responden menurut umur istri sebagian besar yang unmet need KB berusia $>35$ tahun yaitu sebanyak 85 orang $(58,22 \%)$, sedangkan untuk responden yang berusia $<20$ yaitu 2 orang $(1,37 \%)$, tidak ada hubungan yang signifikan antara umur istri dengan kejadian unmet need.
Responden yang unmet need KB berpendidikan tamat $>S M A /$ sederajat yaitu sebanyak 93 orang $(63,7 \%)$, sedangkan yang paling sedikit yang berpendidikan tidak tamat/tamat SD yaitu 17 orang $(11,64 \%)$, tidak ada hubungan yang signifikan antara pendidikan istri dengan kejadian unmet need. Jumlah anak masih hidup sebagian besar responden unmet need $\mathrm{KB}$ yang memiliki anak 1-2 anak yaitu sebanyak 110 orang $(75,34 \%)$, sedangkan paling sedikit yaitu responden yang tidak memiliki anak yaitu 4 orang $(2,74 \%)$, tidak ada hubungan yang signifikan antara jumlah anak masih hidup dengan kejadian unmet need KB.

Saran perlunya sosialisasi Keluarga Berencana (KB) bagi unmeet need khususnya tentang efek samping kontrasepsi untuk menurunkan kebutuhan $\mathrm{KB}$ yang tidak terpenuhi dan meningkatkan kualitas pelayanan KB dengan meningkatkan pemahaman tentang alat kontrasepsi dan keterampilan berkomunikasi yang baik bagi provider dalam memberikan pelayanan KB.

\section{RUJUKAN}

1. Handayani S. PelayananKeluargaBerencana. Yogyakarta: Pustaka Rihama; 2010.

2. Badan Pusat Statistik (BPS), Badan Koordinasi Keluarga Berencana (BKKBN), Departemen Kesehatan, dan Makro Internasional Inc. 2003. Survei Demografi Kesehatan Indonesia (SDKI) 2006-2009. Calverton, Maryland: BPS.

3. Sudarianto.Kepedulian Terhadap Unmet Need Suatu Studi di Kelurahan Kayou Kubu Kecamatan Guguk Pajang Kota Bukit Tinggi [internet]. 2010 [cited 2013 Jun 14]. Available from: http://pasca. unand.ac.id.

4. Ismail, Fitria. Faktor yang Berhubungan dengan Terjadinya Unmet Need KB pada Pasangan Usia Subur (PUS) di Kelurahan Sempaja Selatan Kecamatan Samarinda Utara. 2010. 
5. BKKBN. Profil Hasil Pendataan Keluarga 2011. Jakarta: Direktorat Pelaporan dan Statistik; 2012.

6. Handrina E. Faktor Penyebab Unmet Need Suatu Studi di Kelurahan Kayu Kubu Kecamatan Guguk Panjang Kota Bukittinggi. Sumatera Barat: Universitas Andalas; 2011.

7. Fitriyah N. Hubungan Kesenjangan Pilihan Fertilitas dan Relasi Kuasa Suami Istri dengan Unmet Need Keluarga Berencana (KB): Analisa Data SDKI 2007. Yogyakarta: Fakultas Kedokteran Universitas Gadjah Mada; 2011.

8. Isa. Determinan Unmet Need Keluarga Berencana di Indonesia Analisis Data SDKI 2007. Jakarta: Universitas Indonesia; 2009.
9. Santy P. KekerasanTerhadap Istri dalam Rumah Tangga dan unmet need Pelayanan Keluarga Berencana di Kota Banda Aceh [Tesis]. Yogyakarta: Fakultas Kedokteran Universitas Gadjah Mada; 2011.

10. Triana V. Hambatan Psikososial dan Niat Keluarga Berencana Pada Wanita dengan Kebutuhan Pelayanan Kontrasepsi yang Tidak Terpenuhi (unmet need). Yogyakarta: Universitas Gadjah Mada; 2010.

11. Badan Pusat Statistik (BPS), Badan Koordinasi Keluarga Berencana (BKKBN), Departemen Kesehatan, dan Makro Internasional Inc. 2003. Survei Demografi Kesehatan Indonesia (SDKI) 2006-2009. Calverton, Maryland: BPS; 2007. 